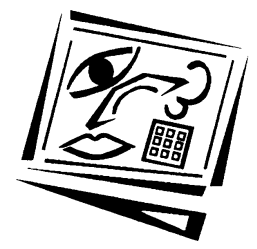

\title{
A web enabled video system for self reflection by student teachers using a guiding framework
}

\author{
Siu Cheung Kong, Ronnie H. Shroff and Hing Keung Hung \\ The Hong Kong Institute of Education
}

\begin{abstract}
To ensure their teaching quality, it is important for student teachers to undertake self reflection on their teaching performance after supervised teaching sessions. With the goal of sharpening the teaching competence of student teachers, a dual function system that uses web based and video based technologies is being developed to facilitate self reflection by student teachers and the teaching supervisory role of teaching supervisors. This article reports on the development of a web enabled video system for encouraging student teachers to reflect on their teaching performance, using a guiding framework. The system enables student teachers to self monitor a video recording process during lessons in teaching practice, and make post-lesson self reflection without the constraints of time and location. Two key features are provided by the system to support student teachers and enhance the quality of reflection. One key feature is a guiding support for self reflection on teaching performance, using a four-dimension framework comprising curriculum planning and evaluation, pupils and pupil-teacher interaction, discipline and classroom management, and professional knowledge of teaching. A second key feature of the system is a 'video bookmark' function for the operationalisation of the reflective process.
\end{abstract}

\section{Introduction}

To equip pre-service teachers with competence in teaching, teacher education should not only provide opportunities to build up professional knowledge and skills, but also encourage reflection on appropriate attitude and strategies for classroom instruction. To this end, teaching practice activities with teaching supervision sessions frequently form a part of programs for teacher education. Student teachers can apply the acquired knowledge and skills in their subject teaching during the lessons in teaching practice, and also reflect on their teaching attitude and strategies in their subject teaching after the lessons in teaching practice.

Self reflection after teaching supervision sessions in teaching practice activities is one of the common approaches for student teachers to ensure their teaching competence. With the goal of enhancing teaching performance of student teachers, a dual function system that capitalises on the use of web based and video based technologies is being developed to foster quality self reflection by student teachers and teaching supervision of teaching supervisors. This article reports upon its development and key features.

\section{Background to the study}

Self reflection is a thinking process in which an individual seriously considers and thoughtfully judges prior experience of the self. The consecutive engagement in self 
reflection commonly leads the self to generate a change in conceptual perspectives (Atkins \& Murphy, 1993; Boyd \& Fales, 1983; Dewey, 1933; Kolb, 1984; Schön, 1983, 1987). Self reflection is considered to be crucial to the development process of student teachers (Hershkowitz \& Schwarz, 1999). According to the schema theory of learning (Anderson, 2005), an individual constructs a mental model on the issue of concern based on prior experience of the self. In line with this thought, researchers in the field of teacher education suggest that the opportunities for student teachers to engage in self reflection after field experience activities enable them to construct their own mental model of teaching practices, based on their field experiences (Kerr, 1981; Northfield \& Gunstone, 1997). Early studies suggest that it is worthwhile to provide student teachers with opportunities to self reflect on their teaching performance in field experience activities, for their personal professional growth and development (Zeichner, 1983, 1995; Zeichner \& Liston, 1996).

Teaching practice is a common type of field experience activity in teacher education. Many teacher training programs require pre-service teachers to undertake self reflection after practice teaching sessions (LaBoskey, 1993; Posner, 2005; Schön, 1987; Zeichner, 1983, 1995). The component of self reflection in teaching practice activities has three significant roles in teacher preparation, namely a useful strategy for developing organising ability to plan lessons; a helpful stimulator for formulating educational philosophy based on personal experience; and an effective means for improving professional practices in classroom instruction (Ball \& Cohen, 1999; Ertmer, Newby \& MacDougal, 1996; Goodfellow \& Sumsion, 2000). With these three roles, the process of self reflection after teaching practice activities enables student teachers to benefit threefold, firstly, by acquiring contextual knowledge about interpretation of classroom situations; secondly, by discerning essential criteria for substantial self reflection; and lastly, by developing emergency responses for unexpected teaching challenges.

For teaching practice activities, student teachers normally engage in self reflection at the stages of in action and on action (Munby \& Russell, 1989, 1993; Russell, 1983; Schön, 1987). Self reflection in action refers to a process in which an individual makes immediate decisions based on observation in the actions; whereas self reflection on action refers to a process in which an individual reflects back on the actions and refines upon the actions. Student teachers usually make a personal automatic reflection during teaching practice activities; and make review at a particular point in time through writing reflective journals after teaching practice activities. Early studies suggest that the capability for effective self reflection on action after lessons in teaching practice is particularly prominent for fostering self directed learning by student teachers for two reasons. Firstly, self reflection on action helps student teachers to improve teaching performance by promoting them to identify the strengths and weaknesses in classroom (Cook \& Duquette, 1999; Garrison, 1992; Schön, 1983, 1987). Secondly, self reflection on action helps student teachers to enhance professional growth, by stimulating them to consider the moral and ethical consequences of choices (Hatton \& Smith, 1994; Kagan, 1992; Kettle \& Sellars, 1996).

A guiding framework is considered crucial for student teachers to make systematic self reflection on teaching performance, because student teachers are mostly not discerning enough to identify the important aspects of teaching practices for their self reflection (Freese, 1999; Parsons \& Stephenson, 2005). Such a framework can serve as a scaffold to explicitly make prompts for self reflection on teaching work, and thus purposefully 
guide student teachers to reframe their teaching experience. The provision of a guiding framework for self reflection helps student teachers to avoid confusion in the self reflection process, and encourages them to develop and externalise reflective thoughts, with a shared language and shared understanding amongst the professional community within their own teaching training institutions (Borko, Michalec, Timmons \& Siddle, 1997; Costa \& Kallick, 2000; Parsons \& Stephenson, 2005).

Researchers in the field of teacher education, including Cook and Duquette (1999), Interstate New Teacher Assessment and Support Consortium (1992), Joram (2007), LaBoskey (1993), Parsons and Stephenson (2005), Posner (2005), and Weiss and Weiss (2001), suggest various frameworks for guiding student teachers to self reflect on their teaching performance. Even though these guiding frameworks vary in scope and focus, they all aim for student teachers to undertake self reflection on teaching performance, with particular attention to the issues about deciding pedagogical contents and teaching activities, selecting learning resources and assessment methods, addressing learning diversity and classroom interaction, and making reflective practice and professional development.

Amongst these guiding frameworks, the work by Cook and Duquette (1999) is the most representative guiding framework for four reasons: it is developed by teaching professionals in the field of teacher education; it targets all student teachers regardless of speciality area; it has a balanced content covering all the key areas of teaching competence; and it has a systematic and precise classification of dimensions for self reflection. This guiding framework directs student teachers to self reflect on their teaching performance in terms of four dimensions. The first dimension, "Curriculum planning and evaluation", focuses on the issues of lesson preparation. The second dimension, "Pupils and pupil-teacher interactions", relates to the issues of studentteacher relations. The third dimension, "Discipline and classroom management", focuses on the mastery of discipline skills. The fourth dimension, "Professional knowledge", relates to the mastery of teaching strategies (Cook \& Duquette, 1999).

In addition to the provision of guiding framework for self reflection, the opportunity to use video based technology is also considered to be constructive for student teachers to undertake quality self reflection (Dymond \& Bentz, 2006; Freese, 1999; Lin, Hmelo, Kinzer \& Secules, 1999). Researchers such as Freese (1999), Robinson and Kelley (2007), and Sherin and van Es, (2005) consider that videos taken during lessons in teaching practice are trustworthy data for student teachers to make a post-lesson self reflection that is grounded in the actual records rather than uncertain recollections. The studies by these researchers also find that student teachers show significant growth in the levels of reflective thoughts about their teaching work, under a guiding framework for self reflection, after browsing video recordings of lessons in teaching practice. The use of videos is thus considered to be helpful in enhancing the depth and quality of self reflection by student teachers.

Video recordings of lessons in teaching practice can provide student teachers with specific information for the analysis and evaluation of their classroom teaching performance, from an observer perspective, with an unlimited access. The creation of electronic platforms for student teachers to store videos of lessons in teaching practice and add comments on teaching performance is one of the possible approaches to promoting the depth and quality of self reflection (Calandra, Brantley-Dias \& Dias, 2006; Sherin \& van Es, 2005). It is because such electronic platforms allow student 
teachers to externalise their reflective thoughts, based on the accurate video recorded data from teaching practice activities. This approach allows student teachers to actively construct applicable knowledge about classroom instruction, develop reflective practices on their teaching work, and take responsibility for their own learning (Munby, Russell \& Martin, 2001; Struyk, Kinder, Cole, Best \& Smith-Shank, 1995).

The use of web enabled, video based systems, which make the production, transition and retrieval of video data executable through the use of virtualisation and remote access software for delivering applications over a network and the Internet, can support student teachers to gain a valuable, learner centred experience in reflective activities for self evaluation of teaching performance (Jonassen, Davidson, Collins, Campbell \& Haag, 1995; Freese, 1999; Robinson \& Kelley, 2007; Schauble, Raghavan \& Glaser, 1993). With the provision of a template for self reflection on a dimensional basis, student teachers can reflect purposefully on their teaching performance after each lesson in teaching practice by browsing the corresponding video clips (see Figure 1).

\begin{tabular}{|c|c|c|c|c|}
\hline \multirow{2}{*}{ Reflection } & \multicolumn{3}{|c|}{ Dimension } \\
\cline { 2 - 5 } & $\begin{array}{c}\text { Curriculum } \\
\text { planning and } \\
\text { evaluation }\end{array}$ & $\begin{array}{c}\text { Pupils and } \\
\text { pupil-teacher } \\
\text { interactions }\end{array}$ & $\begin{array}{c}\text { Discipline and } \\
\text { classroom } \\
\text { management }\end{array}$ & $\begin{array}{c}\text { Professional } \\
\text { knowledge }\end{array}$ \\
\hline $\begin{array}{l}\text { Reflection on } \\
\text { video session \#1 }\end{array}$ & & & & \\
\hline $\begin{array}{l}\text { Reflection on } \\
\text { video session \#2 }\end{array}$ & & & & \\
\hline$\cdot$ & & & & \\
\hline $\begin{array}{l}\text { Reflection on } \\
\text { video session \#n }\end{array}$ & & & & \\
\hline
\end{tabular}

Figure 1: A four-dimension framework for guiding student teachers to undertake post-lesson self reflection with the use of video technology

\section{Criteria for the design of the web enabled video system}

The literature review indicates that there is a positive potential for student teachers to undertake self reflection on teaching performance with the use of video technology. However, there are three limitations in conventional practices for student teachers' use of video technology for self reflection purposes. Firstly, student teachers usually lack an easily accessible, multi-function platform for producing, browsing and managing accurate and systematic records of teaching performance (Calandra et al., 2006; Dymond \& Bentz, 2006). Secondly, student teachers usually lack a comprehensive framework with standardised vocabulary for self reflection on teaching performance (Joram, 2007; Weiss \& Weiss, 2001). Thirdly, student teachers usually lack a convenient tool for supporting the management of experiential learning evidence and operationalisation of their self reflection process (Robinson \& Kelley, 2007; Sherin \& van Es, 2005). These limitations may result in a variation in the depth of self reflection of student teachers, which may affect the formulation of proper teaching belief and pedagogical practice in their future instructional work (Munby et al., 2001). 
With the goal of improving the teaching performance of student teachers, a dual function, web enabled system utilising video technology is being developed for enhancing the quality of self reflection by student teachers and teaching supervision by teaching supervisors. This article reports on its development and the use of a fourdimension guiding framework. The study reported here is based upon the premise that student teachers engage in deeper reflection on their teaching work, after browsing videos of lessons in teaching practice and externalising their post-lesson reflective thoughts. In response to the three limitations in conventional practices for student teachers undertaking self reflection with the use of videos, there were three criteria for the design work:

1. The system should provide an easily accessible, multi-function platform for student teachers to self monitor video and audio recordings of classroom situations, during their teaching practice activities, without assistance from other people.

2. The system should provide a guiding framework for student teachers to underake self reflection on teaching performance when browsing video recordings of their teaching work, free from the constraints of time and location.

3. The system should provide a convenient tool for student teachers to build a collection of experiential learning evidence, and externalise reflective thoughts in terms of important aspects of teaching practices, for a substantial and systematic reflection on their own teaching performance.

\section{Architecture for self monitoring classroom recording}

A web enabled video and audio recording system was designed to support self reflection on action by student teachers. The architecture of the system enables student teachers to take responsibility for self production of actual records of their teaching practice activities. The system was installed in classrooms for student teachers to record their teaching performance in a self monitoring manner. Figure 2 shows the classroom set up of the video system.

The system consists of three components. The first component is wireless Internet Protocol (IP) cameras, two being wall mounted in the designated classroom in the placement school for video recording. The first IP camera was installed at the back of the classroom, facing the blackboard, to capture the teaching performance of the student teacher. The second IP camera was installed beside the blackboard, facing the students of the placement school, to capture student reactions to the teaching work of the student teacher. The second component of the system is digital microphones. The first microphone is for attaching to the clothing of the student teacher and the second was installed above the blackboard, for audio recordings to accompany the video recordings. The third component of the system is a notebook computer, set up in the teaching console for student teachers to self monitor the recording during a practice teaching session.

A software system with a one stop interface for controlling the operation of the wireless IP cameras and the transmission of recorded data was purchased for supporting the self monitoring classroom recording. After customisation, it was installed in the notebook computer for student teachers. This addresses the design criterion that student teachers should be able to use the system for classroom recording without assistance from other people. The interface includes clear icons for the easy control of all necessary shooting functions of the two wireless IP cameras. Student 
teachers can start recording, zoom in and out on the teaching console or student seats, pan across the classroom, stop recording and save video clips by simply pressing the relevant icons on the interface. The videos are uploaded to the video server, displayed and simultaneously saved on the notebook computer, as the session proceeds.

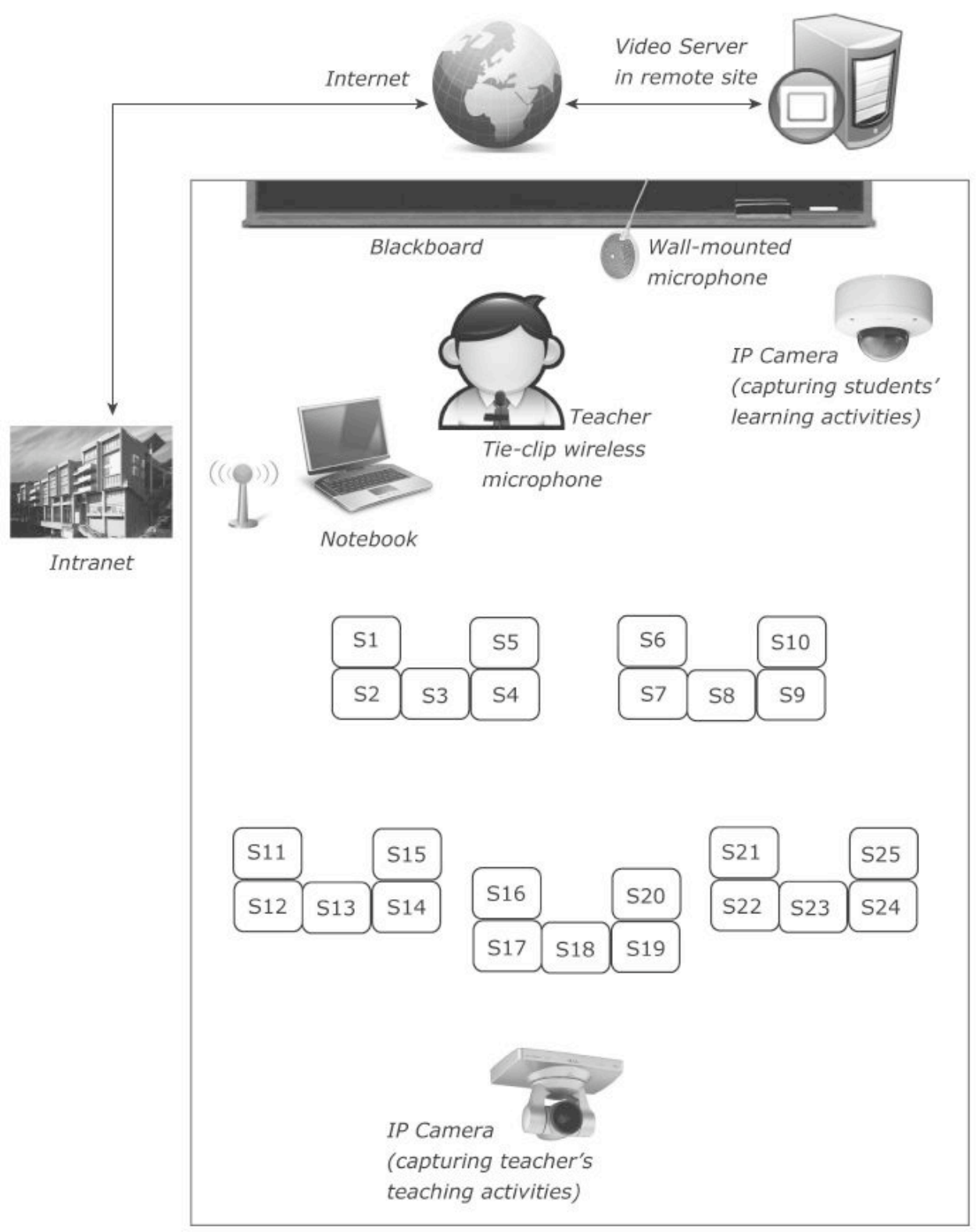

Figure 2: The classroom set up for the web enabled video system

Through the interface, student teachers are allowed to browse the uploaded videos from two different angles in the classroom. There are three screens in this interface: two smaller screens are vertically located on the right hand side of the interface to 
display the classroom situations from the angles at the back of the classroom and beside the blackboard, respectively; one larger screen is centrally located in the interface to display the classroom situation from one of these two angles selected by the student teacher. This helps student teachers to manipulate the shooting process of the wireless IP cameras based on the real time video displays on the notebook computer. Figure 3 shows the one stop interface for self monitoring of the video recording.

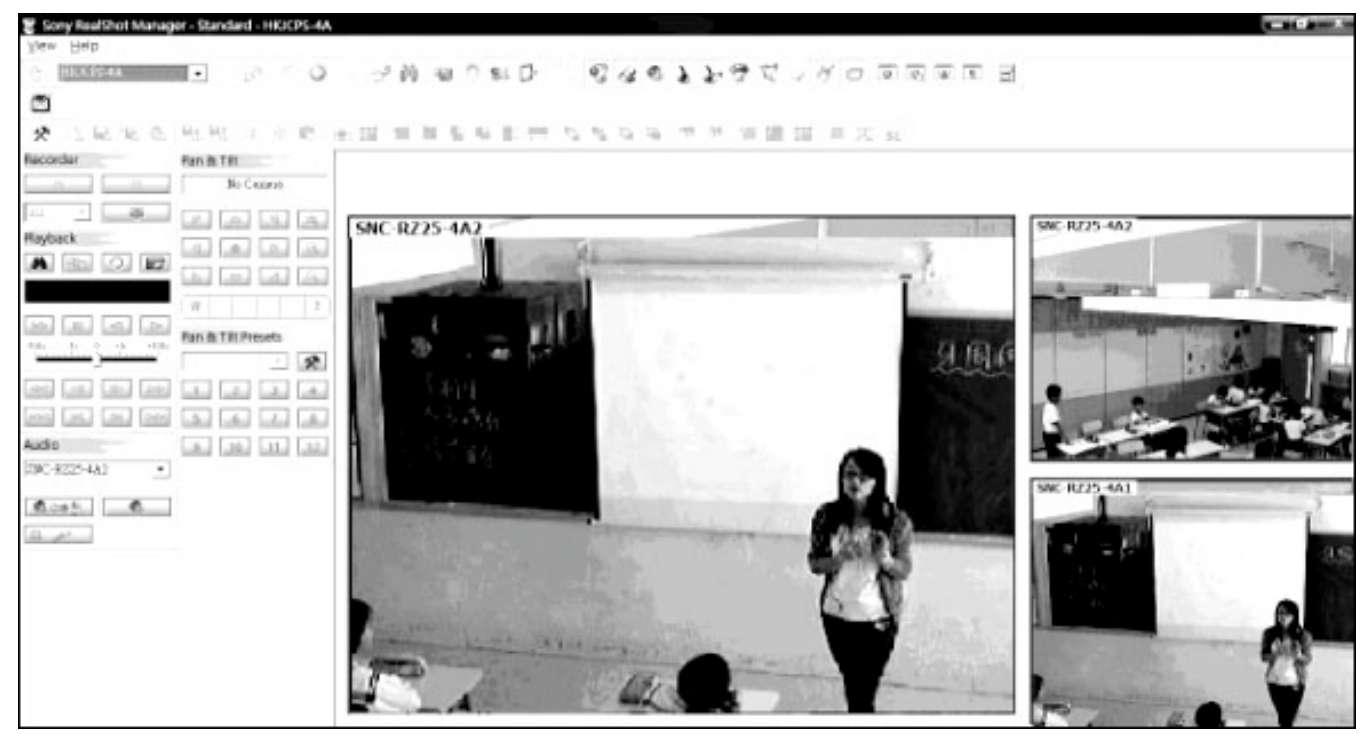

Figure 3: The one stop interface for self monitoring of the video recording

In addition to storage in the notebook computer used, the data is copied to a video database located at a video server in the remote site via the intranet of the placement schools and the Internet. For privacy reasons, the video data for individual student teachers is stored in a video database for which each student teacher has an individual account for login purposes. Student teachers can access only the video clips that capture their own practice teaching. This enables student teachers to conveniently obtain and keep a systematic collection of the experiential learning evidence in their teaching activities, for reflection at a later stage, without following any complicated procedures. Thus it facilitates student teachers' self reflection on action after the teaching practice activities.

The recording system was developed with two criteria: recording of classroom activities is user centred to the extent that student teachers can manipulate the process according to their needs for particular instances; and data storage is very convenient, so that student teachers are not required to upload videos manually onto the database after a practice teaching session. To address the first criterion, the system is designed to instantly display the video data on the notebook computer of the student teacher. This requires $2 \mathrm{Mb} / \mathrm{s}$ of bandwidth capacity for sending the data from the input devices (i.e., the two wireless IP cameras and the two digital microphones) in the classroom through the intranet of the placement school to the Internet, and $2 \mathrm{Mb} / \mathrm{s}$ more of the bandwidth capacity for concurrently transferring data from the Internet to the notebook computer in the classroom for the real time video display (see Figure 4). 


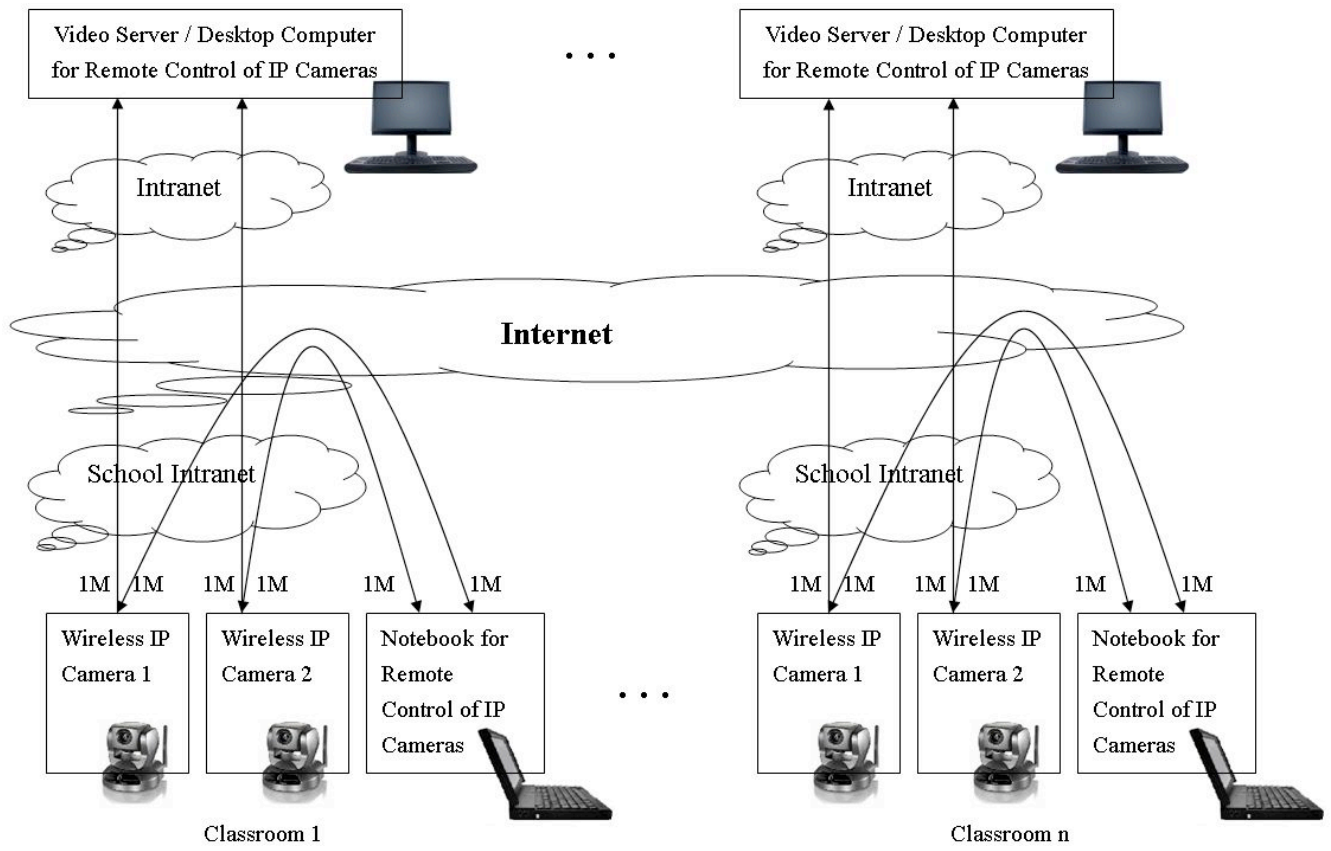

Figure 4: The transmission of video recorded data in the system

To address the latter criterion, the system was designed to simultaneously copy the data to the video server for data storage. This needs $2 \mathrm{Mb} / \mathrm{s}$ of the bandwidth capacity for sending data from the input devices in the classroom to the video server through the intranet of the placement school and then the Internet. As shown in Figure 4, it in turn takes a multiple of $6 \mathrm{Mb} / \mathrm{s}$ of the bandwidth capacity of the placement schools to support the simultaneous operation of the designed system in more than one classroom.

\section{Feature for self reflection under a guiding framework}

One of the key features of the system is the provision of a guiding support for the online self reflection. This addresses the design criterion that student teachers should be able to perform self reflection under a guiding framework in browsing video recordings of their teaching work. A four-dimension guiding framework was adopted to support self reflection on action, and thereby provoke self reflection in action. This feature aims to guide student teachers to discern essential criteria for substantial reflection on teaching performance, and therefore stimulate them to construct their own mental model of educational philosophy and teaching practices, based on field experience. The guiding framework was designed by drawing on the most representative self reflection framework discussed in the previous sections. To prevent student teachers from getting lost in the self reflection process, the categories of evaluation dimensions and the list of evaluation items provide explicit prompts for self reflection. These prompts help student teachers to precisely externalise their reflective thoughts.

The four dimensions in the guiding framework address a mix of issues about cognitive competence and affective knowledge required by teaching professionals. The first 
dimension, "Curriculum planning and evaluation", focuses on the ability to set learning objectives, select instructional contents and plan learning activities. Five evaluation items, "Learning objectives", "Content knowledge", "Choice of content", "Structuring of learning activities" and "Lesson plan" are devised. The second dimension, "Pupils and pupil-teacher interaction", relates to the issues of teaching attitude and teacher-student relationship. Three evaluation items, "Attitude in teaching", "Relationship with learners" and "Catering for learner differences", are included. The third dimension "Discipline and classroom management" focuses on the capability of managing resources, environments and strategies for teaching and learning. Three evaluation items "Management of learning environment", "Selection and use of resources" and "Implementation of teaching and learning strategies" are made. The fourth dimension, "Professional knowledge of teaching", relates to the issues of assessment method, feedback provision and classroom interaction. Four evaluation items, "Using assessment to enhance learning", "Providing feedback", "Verbal and non-verbal communication" and "Classroom interaction", are included. The electronic self reflection forms for the guiding framework incorporates these dimensions into the web based video system.

The electronic self reflection forms (Figure 5) provide self rating functions to guide student teachers to articulate their perception of their practice teaching performance in a structured manner. Radio buttons for the ranking of "Distinction", "Credit", "Pass" and "Fail" are offered for convenient online self evaluation of teaching performance under an itemised approach. The electronic self reflection forms also provide text entry boxes for student teachers to self evaluate their teaching performance in an unstructured manner by entering additional reflective statements.

To support student teachers to substantially and flexibly develop reflective practices on teaching work according to their own needs, the system provides two versions of electronic forms for self reflection, namely "Before video browsing" and "After video browsing" version. The difference between the two versions is that the columns "Reflections" and "Overall reflections" in the "After video browsing" version allow student teachers to insert video links in addition to textual comments.

The system requires student teachers to complete the "Before video browsing" form prior to online access to the video database. Student teachers are requested to make self reflection on their teaching performance, before browsing their videos. This ensures that the student teachers make self reflection on action, both before and after browsing videos. Afterwards, student teachers can access the online video browsing platform to view videos of lessons in teaching practice. After browsing, student teachers are allowed to complete the "After video browsing" version of the self reflection form via two approaches. Student teachers can open a blank "After video browsing" form to enter their reflective statements, or they can fill in an "After video browsing" form based on their completed "Before video browsing" form, which is permanently unchangeable and is stored in the system for subsequent retrieval.

\section{The video bookmark function}

Another key feature of the system is a video bookmark function for the operationalisation of reflective process. This feature addresses the design criterion that student teachers should be able to collect a pool of experiential learning evidence and externalise reflective thoughts in terms of the important aspects in teaching practices 


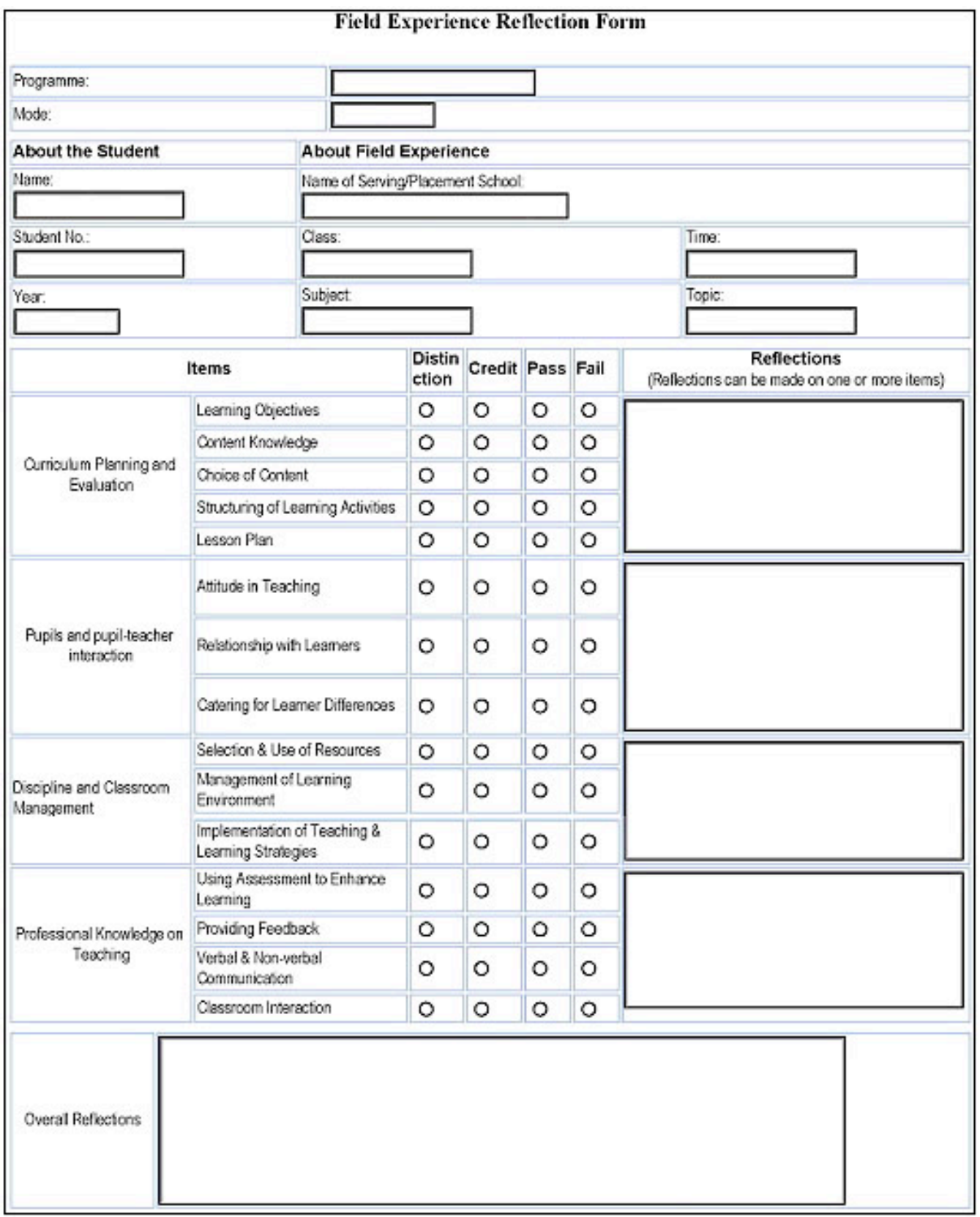

Figure 5: The electronic form designed for self reflection by student teachers after teaching practice activities

for substantial reflection. Student teachers can "bookmark" a segment of video clips concerning noteworthy teaching behaviours, and then enter their corresponding reflective statements and future emergency responses on their teaching performance as depicted in that particular video segment. The system allows student teachers to store more than one bookmarked video segment for an individual self reflection dimension, 
and add a certain bookmarked video segment to the column for "Reflection", for more than one self reflection dimension in the electronic form (see Figure 6). Student teachers are also allowed to delete the bookmarked video segments at a later stage.

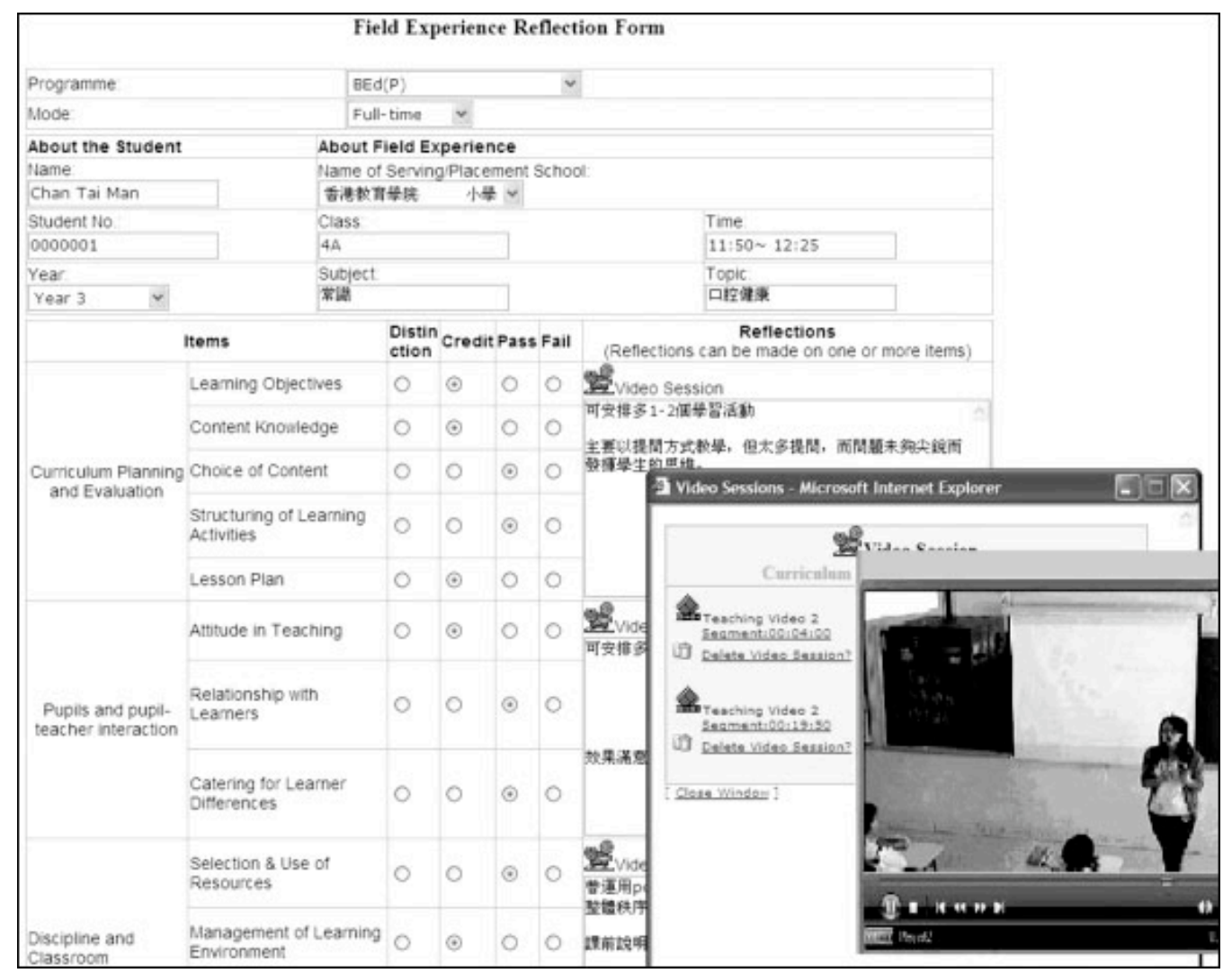

Figure 6: Viewing bookmarked video segment for online self reflection after teaching practice activities

With the assumption that student teachers make a deeper reflection on their teaching performance after browsing videos of lessons in teaching practice, the video bookmark function encourages them to experience the difference in the depth of self reflection with different availabilities of concrete teaching evidence before and after video browsing. Self reflection with video bookmarking helps to stimulate student teachers to discern and subsequently realise the teaching behaviours considered important for their future teaching work. The video bookmark function creates a self directed learning opportunity for student teachers to interpret their teaching behaviours deeply, systematically reframe their teaching experiences, and actively refine their teaching practices via a learner centred approach. This feature helps student teachers to keep a collection of evidence for learning that reveals concretely the strengths and weaknesses of their teaching performance, and prompts them to operationalise the process of self reflection on their teaching practices. 


\section{Conclusion}

Self reflection on performance after student teachers' practice activities is considered to be a critical approach to supporting the development of teaching quality. The use of video based technology is considered advantageous to student teachers in making in depth self reflection on their teaching performance. With the goal of sharpening the teaching competence of student teachers, this article reported the architecture and features of the web enabled video system that fosters self reflection on teaching performance, using a four-dimension framework. The system assists student teachers to self produce a real time record of teaching work, undertake systematic self reflection based on videos of teaching practice activities, and manage an accurate and systematic record of teaching performance without being constrained by time and location.

An empirical study was conducted to investigate the effectiveness of the system for fostering self reflection by student teachers on their teaching performance. A number of student teachers who were taking undergraduate programs with various subject specialisations were invited to participate in a two-round teaching activity involving the use of the system. In each of the two rounds of teaching activity, the students were asked to use the system to self monitor their recording of the classroom situation during the practice teaching, and undertake primary self reflection on their teaching performance based on the guiding framework. After the second round of teaching activity, the invited student teachers were individually interviewed about their views on the appropriateness and usability of the system, and their perception of the changes in the self reflection process with use of the system.

From the preliminary data, two implications are drawn for the use of the system in the real classroom environment. The first issue relates to collaborative support from the stakeholder groups in the placement schools. Prior to planning for use of the system for in class video recording, the teacher training institution should seek approval from the principals of the placement schools for the installation of the system in school classrooms. Consents from teachers and parents need be obtained for the use of the system in practice teaching activities. At the beginning of each lesson, students in the placement schools should be informed about the use of the system for classroom recording. These initiatives help to reduce the uncertainty and interference that may be caused by the use of the system in real classroom environments.

The second issue is related to orientation work for student teachers, prior to practice teaching involving use of the system. Teacher training institutions should inform student teachers clearly about the rationale and process, and also remind them about the potential benefits and noteworthy issues, when using the system to scaffold the self reflection process. These initiatives help to increase student teachers' interest in and willingness to use the system.

Every teacher training institution has an in house framework for evaluation of the teaching competence of student teachers. Teacher training institutions may fine tune the list of self evaluation criteria in the system's electronic self reflection forms, according to their own frameworks. The teacher education sector can therefore capitalise on the use of the system, which enables student teachers to self reflect on their teaching performance, from the perspectives of an insider in the teaching profession. This contributes to a consistent quality control work on the teaching quality of student teachers. 


\section{Acknowledgments}

The authors would like to acknowledge the support of a research grant from the Hong Kong Institute of Education for the project "A study analysing reflections of student teachers on using a web enabled, self monitoring video system in classroom for enhancement of teaching quality".

\section{References}

Anderson, J. R. (2005). Cognitive psychology and its implications (6th edition). New York: Worth.

Atkins, S. \& Murphy, K. (1993). Reflection: A review of the literature. Journal of Advanced Nursing, 18(8), 1188-1192.

Ball, D. L. \& Cohen, D. K. (1999). Developing practice, developing practitioners: Toward a practice-based theory of professional development. In L. Darling-Hammond \& G. Skyes (Eds), Teaching as the learning professional: Handbook of policy and practice (pp. 3-32). San Francisco: Jossey-Bass.

Borko, H., Michalec, P., Timmons, M. \& Siddle, J. (1997). Student teaching portfolios: A tool for promoting reflective practice. Journal of Teacher Education, 48(5), 345-357.

Boyd, E. \& Fales, A. (1983). Reflecting learning: Key to learning from experience. Journal of Humanistic Psychology, 23(2), 99-117.

Calandra, B., Brantley-Dias, L. \& Dias, M. (2006). Using digital video for professional development in urban schools: A preservice teacher's experience with reflection. Journal of Computing in Teacher Education, 22(4), 137-145.

Cook, S. A. \& Duquette, C. (1999). Professional development schools: Preservice candidates' learning and sources of knowledge. Alberta Journal of Educational Research, 45(2), 198-207.

Costa, A. L. \& Kallick, B. (2000). Getting into the habit of reflection. Educational Leadership, 57(7), 60-62.

Dewey, J. (1933). How we think. Boston, DC: Heath and Company.

Dymond, S. K. \& Bentz, J. L. (2006). Using digital videos to enhance teacher preparation. Teacher Education and Special Education, 29(2), 98-112.

Ertmer, P. A., Newby, T. J. \& MacDougal, M. (1996). Students' responses and approaches to casebased instruction: The role of reflective self-regulation. American Educational Research Journal, 33(3), 719-752.

Freese, A. R. (1999). The role of reflection on pre-service teachers' development in the context of a professional school. Teaching and Teacher Education, 15(8), 895-909.

Garrison, D. R. (1992). Critical thinking and self-directed learning in adult education: An analysis of responsibility and control issues. Adult Education Quarterly, 42(3), 136-148.

Goodfellow, J. \& Sumsion, J. (2000). Transformative pathways: Field-based teacher educators' perceptions. Journal of Education for Teaching, 26(3), 245-257.

Hatton, N. \& Smith, D. (1994). Reflection in teacher education: Towards definition and implementation. Teaching and Teacher Education, 11(1), 33-49. 
Hershkowitz, R. \& Schwarz, B. (1999). Reflective processes in a mathematics classroom with a rich learning environment. Cognition and Instruction, 17(1), 65-91.

Interstate New Teacher Assessment and Support Consortium (INTASC) (1992). Model standards for beginning teacher licensing and development: A resource for state dialogue. [viewed 12 Jan 2009, verified 31 Aug 2009]. http:/ / www.ccsso.org/content/pdfs/ corestrd.pdf

Jonassen, D., Davidson, M., Collins, M., Campbell, J. \& Haag, B. B. (1995). Constructivism and computer-mediated communication in distance education. The American Journal of Distance Education, 9(2), 7-27.

Joram, E. (2007). Clashing epistemologies: Aspiring teachers', practicing teachers', and professors' beliefs about knowledge and research in education. Teaching and Teacher Education, 23(2), 123-135.

Kagan, D. M. (1992). Professional growth among pre-service and beginning teachers. Review of Educational Research, 62(2), 129-169.

Kerr, D. H. (1981). The structure of quality in teaching. In Soltis, J. F. (Ed), Philosophy and education (pp. 61-93). Chicago: University of Chicago Press.

Kettle, B. \& Sellars, N. (1996). The development of students' practical theory of teaching. Teaching and Teacher Education, 12(1), 1-24.

Kolb, D. (1984). Experiential learning: Experience as a source of learning and development. Englewood Cliffs, NJ: Prentice Hall.

LaBoskey, V. (1993). A conceptual framework for reflection in preservice teacher education. In J. Calderhead \& P. Gates (Eds), Conceptualising reflection in teacher development (pp. 23-38). London: The Falmer Press.

Lin, X., Hmelo, C., Kinzer, C. K. \& Secules, T. J. (1999). Designing technology to support reflection. Educational Technology Research and Development, 47(3), 43-62.

Munby, H. \& Russell, T. (1989). Educating the reflective teacher: An essay review of two books by Donald Schön. Journal of Curriculum Studies, 21(7), 71-80.

Munby, H. \& Russell, T. (1993). Reflective teacher education: Technique or epistemology? Teaching and Teacher Education, 9(4), 431-438.

Munby, H., Russell, T. \& Martin, A. K. (2001). Teachers' knowledge and how it develops. In V. Richardson (Ed), Handbook of research on teaching (pp. 877-904). Washington, DC: American Educational Research Association.

Northfield, J. \& Gunstone, R. (1997). Teacher education as a process of developing teacher knowledge. In J. Loughran \& T. Russell (Eds), Teaching about teaching: Purpose, passion and pedagogy in teacher education (pp. 48-56). London: Falmer Press.

Parsons, M. \& Stephenson, M. (2005). Developing reflective practice in student teachers: Collaboration and critical partnerships. Teachers and Teaching, 11(1), 95-116.

Posner, G. J. (2005). Field experience: A guide to reflective teaching (6th edition). Boston, MA: Pearson/Allyn and Bacon.

Robinson, L. \& Kelley, B. (2007). Developing reflective thought in preservice educators: Utilizing role-plays and digital video. Journal of Special Education Technology, 22(2), 31-43. 
Russell, T. L. (1983). Analyzing arguments in science classroom discourse: Can teachers' questions distort scientific authority? Journal of Research in Science Teaching, 20(1), 27-45.

Schauble, L., Raghavan, K. \& Glaser, R. (1993). The discovery and reflection notation: A graphical trace for supporting self regulation in computer-based laboratories. In S. D. Lajoie \& S. J. Derry (Eds), Computers as cognitive tools (pp.319-337). Hillsdale, NJ: Lawrence Erlbaum Associates.

Schön, D. A. (1983). The reflective practitioner: How professionals think in action. New York: Basic Books.

Schön, D. A. (1987). Educating the reflective practitioner: Toward a new design for teaching and learning in the professions. San Francisco: Jossey-Bass.

Sherin, M. G. \& van Es, E. A. (2005). Using video to support teachers' ability to notice classroom interactions. Journal of Technology and Teacher Education, 13(3), 475-491.

Struyk, L. R., Kinder, D., Cole, K. B., Best, K. \& Smith-Shank, D. (1995). Utilizing multimedia applications to enhance instruction of performance assessment for pre-service teachers. Journal of Educational Computing Research, 13(3), 227-236.

Weiss, E. M. \& Weiss, S. (2001). Doing reflective supervision with student teachers in a professional development school culture. Reflective Practice, 2(2), 125-154.

Zeichner, K. M. (1983). Alternative paradigms of teacher education. Journal of Teacher Education, 34(3), 3-9.

Zeichner, K. M. (1995). Reflections of a teacher educator working for social change. In T. Russell \& F. Korthagen (Eds), Teachers who teach teachers: Reflections on teacher education (pp. 11-24). Washington, DC: Falmer Press.

Zeichner, K. M. \& Liston, D. P. (1996). Reflective teaching: An introduction. Mahwah, NJ: Lawrence Erlbaum Associates.

Dr Siu Cheung KONG (Corresponding author), Head and Associate Professor, Department of Mathematics and Information Technology, The Hong Kong Institute of Education. Postal: 10 Lo Ping Road, Tai Po, New Territories, Hong Kong, China. Email: sckong@ied.edu.hk Web: http:/ / www.ied.edu.hk/mit/en/staff/sckong.htm

Dr Ronnie H. SHROFF, Post-doctoral Research Fellow, Centre for Learning, Teaching and Technology, The Hong Kong Institute of Education. Postal: 10 Lo Ping Road, Tai Po, New Territories, Hong Kong, China. Email: rshroff@ied.edu.hk Web: http:/ / www.ied.edu.hk/lttc/about/staff/ronnie.html

Mr Hing Keung HUNG, Assistant Education Technology Officer, Centre for Learning, Teaching and Technology, The Hong Kong Institute of Education. Postal: 10 Lo Ping Road, Tai Po, New Territories, Hong Kong, China. Email: vhung@ied.edu.hk Web: http:/ / www.ied.edu.hk/lttc/about/staff/vincent.html 